\title{
Do Africans really need to go overseas for Phaco training? Performance audit of a locally trained phaco surgeon in rural Kenya
}

Jean Claude Niyonzima ( $\square$ claudeniyonzima@gmail.com )

Ispahani Islamia Eye Institute and hospital https://orcid.org/0000-0002-7329-5343

Stephen Gichuhi

University of Nairobi

Sarah Sitati

Kenyatta National Hospital

Ernest Ollando

Moi Teaching and Referral Hospital

Research article

Keywords: Phacoemulsification surgical technique, training, visual outcomes

Posted Date: November 20th, 2019

DOI: https://doi.org/10.21203/rs.2.17535/v1

License: (c) (i) This work is licensed under a Creative Commons Attribution 4.0 International License. Read Full License 


\section{Abstract}

Purpose: To audit phacoemulsification cataract surgeries performed independently after a short - term training completed in a rural hospital in Kenya, and to benchmark the outcomes against WHO recommendations.

Methods: This retrospective case-series study recruited patients who had had phacoemulsification cataract surgery at Sabatia Eye Hospital from January to December 2018. All the surgeries were performed by a single surgeon following a brief training in the same center. Data were collected retrospectively using a detailed questionnaire.

Results: Of the one hundred and twenty eyes operated on during this period, one-hundred and sixteen eyes of 86 patients met the inclusion criteria. The mean age was 62 years and the majority of the eyes $(83.6 \%)$ had vision less than $6 / 18$ preoperatively. Co-morbidities included diabetic retinopathy $(3.4 \%)$, age-related macular degeneration (2.6\%), trauma (1.7\%) and glaucoma (0.9\%). Surgical complications were not severe enough to affect the final best-corrected visual acuity, unlike the comorbidities that were negatively correlated with visual outcomes ( $p$-value $<0.001$ ). Good outcomes were $81 \%$ against a WHO target of $80 \%$ for uncorrected visual acuity category, and $96.6 \%$ in the best-corrected visual acuity category against a target of $90 \%$. The Royal College of Ophthalmology database of cataract surgery outcomes and the European Registry of Quality Outcomes for cataract and refractive surgery had comparable results.

Conclusions: This local training model was based on apprenticeship and skills transfer. It can achieve high-quality visual outcomes meeting WHO recommendations.

\section{Significance Of The Study}

Phacoemulsification cataract surgery is still not common practice in the developing world although there is growing demand from informed public. Many ophthalmologists usually have to travel overseas to get this surgical skill. This study presents the results of a performance audit for a young phaco-surgeon trained in a rural hospital in Kenya. The good outcomes reported are expected to encourage the development of more training centers in Africa and hence the popularization of the surgical technique to meet the growing public demand.

\section{Background}

Learning a new surgical technique is a stressful and multifactorial task that requires a conducive learning environment. Ocular surgical training in particular, presents the challenge of producing good visual outcomes for the patient while allowing the trainee to learn good surgical skills. This entails a high level of caution for both trainer and trainee. For the former, it is about equipping a surgeon who will be able to operate safely, while for the later, it is about gathering a skill set within a limited time and using those 
skills to operate independently. In many instances, when the surgeon is released after training, he is primarily responsible for the safety of his patients.

Performed for the first time in New York in 1967 by Charles David Kelman,[1] phacoemulsification cataract surgery (PCS), though a fairly well established surgical technique, is not common practice in developing countries. Visual needs in patients with cataract are quite diversified, ranging from vision restoration in many patients with mature cataracts to more precise vision in patients who present with vision better than 6/18. [2,3] Although small incision cataract surgery (SICS) with posterior chamber lens implantation has gained popularity recently in limited-resource regions, there is increased demand for PCS. [2,4-6]

Residency programs in Africa, including in Kenya, have placed higher emphasis on learning SICS rather than PCS. Because of this, ophthalmologists who desired to train for this skill had to travel abroad, mostly to India. It is believed that Indian training centers are preferred because of the high volumes of patients and hands-on exposure given to trainees. However, it is also true that the training becomes expensive when traveling costs, accommodation, and other daily costs add up. Socially, different cultures, food, and language may adversely affect the learning experience. Training institutions in developed countries have set standards for residency programs on how many phacoemulsification surgeries must be performed before ophthalmologists graduate.[7] These high numbers may, however, be unrealistic in many low- and middle-income countries of the world. Challenges in this setting include low human resources and the absence of equipment, which may extend the training period for the trainee [8]. Producing high numbers of surgeons to respond to a human resource crisis may be a priority that is questionable in terms of quality assurance. Indeed, it is now known that many patients lose their vision after cataract surgery in many countries. $[9,10]$ Moreover, for all cataract surgeries, WHO recommends postoperative uncorrected visual acuity (UCVA) and best- corrected visual acuity (BCVA) equal or better than $6 / 18$ in at least $80 \%$ and $90 \%$ of operated eyes respectively.[11]

The learning experience for surgeons-in-training for any intraocular surgery remains undocumented and unpublished in Kenya, especially for surgeons trained locally in their practice environment.[12] Apprenticeship and skill hand-over is a common practice in surgical training. This may be more so in countries that do not have the resources to train abroad. This audit was therefore done to determine whether this is an effective method of training by assessing the outcomes of a trainee trained in his local environment. It is important to audit the quality of phacoemulsification surgeries with an aim to improve the surgeon's performance and maintain evidence-based cataract surgeries guidelines.[13,14]

\section{Methods}

\section{Study design, surgeon, patients and procedures}


This was a retrospective case-series study with an aim to audit visual outcomes of patients who had phacoemulsification cataract surgery performed from January to December 2018, at Sabatia Eye Hospital. All the surgeries were performed by a single surgeon following a brief surgical training in the same center.

The surgeon was trained by a senior consultant over a period of six months, one day a week, operating on one to two patients on Thursdays. This added up to 34 supervised surgeries performed with or without assistance from March to October 2017. Data were then collected for patients who had PCS in the immediate post-training period. No mentor was available for supervision during the study period.

Records were retrieved for 86 patients with 116 eyes who had PCS done during this period. Patients who had undergone PCS had had the choice between PCS and SICS, except when the nucleus was too hard for the technique. All the patients had biometry done before surgery, with IOL formulas selected according to the axial length of each eye. SRK-T was used for normal axial length (22.5-24.5mm), Hoffer-Q was preferred for axial length less than $21 \mathrm{~mm}$, Holladay 1 or Hoffer Q for an axial length between 21 and 21.49mm. Holladay1 or Hoffer Q or SRK-T were used interchangeably if the axial length was between 23.5 and $25.99 \mathrm{~mm}$. Barret was preferred for high myopia and Haigis for high hyperopia. However, the machine did not have the newer formulas like Barret Universal or Olsen that are currently being used in better-equipped hospitals.

Informed consent was obtained for all patients before surgery. The operating theatre was equipped with a Laureate World Phaco systems machine (Alcon). All the patients had local anesthesia injected in the peribulbar space pre-operatively. A clear corneal incision with a $2.75 \mathrm{~mm}$ Clearcut Alcon blade along with two side-ports to allow bimanual irrigation and aspiration technique was routinely performed. The incision was either temporal or superior, the choice being initially temporal and later guided by the biometric axis. Divide and conquer and Stop and Chop phaco techniques were used depending on the nucleo-sclerosis status. A Foldable posterior chamber intraocular lens was then inserted. Day one postoperative review was mandatory for all patients. Those who came from far were admitted overnight in the hospital. They were all treated with steroids and antibiotics drops and came for a second visit after two weeks, then after one month. Refraction was done at 6 weeks or later. The final visual acuity was recorded at a minimum of six weeks.

\section{Inclusion criteria}

Adults patients' eyes operated for cataract with phacoemulsification technique from January to December 2018 by the post-training surgeon. 


\section{Exclusion criteria}

Patients who did not complete at least six weeks follow-up after surgery, patients who had PCS elsewhere or during the training period were excluded.

\section{Data management}

An Excel spreadsheet file was used to capture the data to be exported to IBM Statistics SPSS version 23 software for Mac for descriptive analysis, means comparison and correlation. Paired-samples T-test was used to compare preoperative and postoperative means. Pearson correlation was used to establish correlations between variables and significance level set at $99 \%$ confidence interval. A P-value of less than 0.05 was considered statistically significant for the rest of the analysis.

\section{Consent to participate and ethical approval}

Every patient signed an informed consent prior to surgery. This study was approved by the Jomo Kenyatta University of Agriculture and Technology Ethical and Research Committee.

\section{Consent to publish}

This was an audit and patients were not directly involved. Data recorded for analysis were anonymized, no personal data or images will be published at any time. The authors adhered to the tenants of the declaration of Helsinki throughout the study.

\section{Patient and public involvement}


While patients were not directly involved, two members of the public were recruited for data collection and their respective datasets were confronted for accuracy.

\section{Results}

\section{Sociodemographic characteristics}

Eighty-six patients aged between 23 and 85 (mean age $62.37 \pm 12.06$ years) had phacoemulsification cataract surgery on 116 eyes, between January and December 2018.

There were more females (55\%) than males (45\%) who came for PCS though the difference was not statistically significant (P-value:0.45).

\section{Preoperative characteristics}

For a total of 116 eyes, 63 were left eyes. Only 25 eyes $(21,6 \%)$ had a visual acuity of 6/18 (0.48 Log MAR) or better prior to PCS while 44 eyes (37.6\%) had poor vision less than 6/60 (1 Log MAR). Diabetic retinopathy, age-related macular degeneration, glaucoma, trauma were the main comorbidities.

All the eyes had biometric readings before surgery, K1 mean was $43.08 \mathrm{D}$ (SD: 1.61D), K2 mean was $43.89 \mathrm{D}$ (SD: $1.75 \mathrm{D}$ ). The axial length was $23.31 \pm 0.9 \mathrm{~mm}$ and the IOL power $20.3 \pm 1.9 \mathrm{D}$.

The superior incision was performed only on 3 eyes, the rest had a temporal incision.

\section{Surgical complications}

Table 1 presents the intraoperative and postoperative complications respectively. 
Minor complications included leaking side ports, small rhexis, small pupil that ranged between 1.7-5.2\%.

Complications that threatened the safety of the surgery include extended rhexis, posterior capsular rupture, vitreous prolapse, corneal edema and postoperative uveitis.

In one patient, a 'never event' complication occurred, a different IOL power was inserted and required to be exchanged the next day.

Other reasons for returning to theatre were severe exudative inflammation that occurred exclusively in patients who had the same type of IOL. The IOL was used for six patients, four of them had an inflammatory reaction and two were re-admitted for anterior chamber washout and periocular steroid injection.

Despite having five posterior capsule ruptures, no patient was left aphakic nor did a retinal detachment happen.

Some eyes had more than one surgical complication. This was the case for instance in patients in whom the posterior capsule rupture occurred with subsequent vitreous prolapse and IOL eventually inserted in the sulcus.

\section{Table 1: surgical complications}




\begin{tabular}{|l|l|}
\hline Intraoperative complications & Frequency (\%) \\
\hline Leaking side ports & $2(1.7)$ \\
\hline Small pupil & $5(4.3)$ \\
\hline Small rhexis (diameter<5mm) & $6(5.2)$ \\
\hline Extended rhexis & $3(2.6)$ \\
\hline Posterior capsule rupture & $5(4.3)$ \\
\hline Zonular disruption & $1(0.8)$ \\
\hline Vitreous prolapse & $4(3.4)$ \\
\hline Wrong IOL power & $1(0.8)$ \\
\hline Dropped nucleus/IOL & $0(0.0)$ \\
\hline Postoperative complications & Frequency (\%) \\
\hline corneal edema & $7(6.0)$ \\
\hline uveitis & $4(3.4)$ \\
\hline Second surgery on the same eye & $3(2.6)$ \\
\hline Aphakia & $0(0.0)$ \\
\hline Endophthalmitis & $0(0.0)$ \\
\hline Retinal detachment & $0(0.0)$ \\
\hline
\end{tabular}

\section{Postoperative visual outcomes}

Table 2 presents postoperative visual acuities at day one and after six weeks.

The good visual acuity that was observed in $21.6 \%$ of eyes prior to surgery improved to $81,9 \%$ and $97.4 \%$ in the postoperative uncorrected and best-corrected visual acuity categories respectively.

The borderline category was reduced after refraction from $16.4 \%$ to $1.7 \%$. The same trend is also noted in the poor visual acuity category that passed from $38 \%$ before surgery to $2.6 \%$ with uncorrected visual acuity and $1.7 \%$ after refraction and correction. (Figure 1)

In the 'uncorrected visual acuity' category, the good VA hit the target (81\% vs $80 \%$ ). However, the study results showed a slightly higher borderline visual acuity proportion 
(16.1\% vs 15\%). (Figure 1). The study scored $96,6 \%$ of good visual acuity. (Figure2)

Table 2: postoperative visual outcomes at day 1 and six weeks later

\begin{tabular}{|c|c|c|}
\hline \multicolumn{3}{|c|}{ Postoperative day 1 uncorrected visual acuity } \\
\hline Visual acuity (Log MAR) & Eyes (\%) & Cumulative Percentage \\
\hline 0.00 & $13(11.2)$ & 11.2 \\
\hline 0.08 & $1(0.9)$ & 12.1 \\
\hline 0.18 & $34(29.3)$ & 41.4 \\
\hline 0.30 & $38(32.8)$ & 74.1 \\
\hline 0.48 & $13(11.2)$ & 85.3 \\
\hline 0.60 & $5(4.3)$ & 89.7 \\
\hline 1.00 & $1(0.9)$ & 90.5 \\
\hline 1.20 & $3(2.6)$ & 93.1 \\
\hline 1.30 & $8(6.9)$ & 100.0 \\
\hline Total & $116(100)$ & \\
\hline \multicolumn{3}{|c|}{ Postoperative uncorrected visual acuity at 6 weeks or later } \\
\hline Visual acuity & Eyes (\%) & Cumulative Percentage \\
\hline \multicolumn{3}{|l|}{ (Log MAR) } \\
\hline 0.00 & $7(6.0)$ & 6.0 \\
\hline 0.18 & $45(38.8)$ & 44.8 \\
\hline 0.30 & $16(32.8)$ & 58.6 \\
\hline 0.48 & $27(13.8)$ & 81.9 \\
\hline 0.60 & $11(9.5)$ & 91.4 \\
\hline 1.00 & $1(0.9)$ & 92.2 \\
\hline 1.30 & $9(7.8)$ & 100.0 \\
\hline Total & $116(100)$ & \\
\hline \multicolumn{3}{|c|}{ Postoperative best-corrected visual acuity at 6 weeks or later } \\
\hline Visual acuity & Eyes (\%) & Cumulative Percentage \\
\hline \multicolumn{3}{|l|}{$(\log M A R)$} \\
\hline-0.10 & $1(0.9)$ & 0.9 \\
\hline 0 & $77(66.4)$ & 67.2 \\
\hline 0.18 & $30(25.9)$ & 93.1 \\
\hline 0.30 & $4(3.4)$ & 96.6 \\
\hline 0.48 & $1(0.9)$ & 97.4 \\
\hline 0.78 & $1(0.9)$ & 98.3 \\
\hline 1.00 & $1(0.9)$ & 99.1 \\
\hline 1.30 & $1(0.9)$ & 100.0 \\
\hline Total & $116(100)$ & \\
\hline
\end{tabular}


There was a negative correlation between presence of comorbidities and the best-corrected visual acuity (Pearson: -0.614, P-value: 0.001). However, the laterality (P-value: 0.861) and complications (P-value:0.681) were not correlated to the final visual acuity.

\section{Postoperative refractive error (Spherical equivalent)}

The postoperative refractive error was calculated as spherical equivalent. The postoperative refractive error mean was $-0.71 \mathrm{D} \pm 0.96 \mathrm{D}$ spherical equivalent, whereas the cylinder mean was $-0.64( \pm 0.5 \mathrm{D})$. The postoperative astigmatism was statistically lower compared to the preoperative one (P-value $<0.001$ ).

Although the surgeon targeted a refractive error of less than -1D, it was obtained only in $53.5 \%$ of eyes. An important proportion of eyes had a refractive error comprising between $-1 \mathrm{D}$ and $+1 \mathrm{D}$ (77 eyes, 66.57\%). Overall, the residual refractive error was myopia in $98 \%$ of eyes, of which $4.3 \%$ had $-3 \mathrm{D}$ or more. (Figure 3 )

\section{Discussion}

Eighty-six of ninety participants completed the study period follow-ups. This was a good rate compared to other setups.[15,16]

Fifty-five percent of participants were female. Their longevity and health-seeking behaviour are generally known to surpass that of their fellow males.[17-20]

The mean age (62 years) was consistent with most studies because cataract is generally age-related. The mean age may be lower compared to other studies where the general population mean age is higher or because the cataract surgery threshold is different.[15,18,19,21]

Generally, the pre-operative visual acuity was poor to moderate; comparable to that found in other low and middle-income countries like Nigeria, India and Saudi Arabia. $[6,16,18]$ Lack of awareness on cataract and its management, plus fear to have an intraocular surgery were recently reported by Gabbott et a.I in Kwale County in Kenya as factors associated with late cataract surgery.[22]

The mean axial length was 23.31+/- $0.94 \mathrm{~mm}$. Earlier in 2009, a study was conducted in Kwale District Eye Hospital (Kenya) and found a very similar axial length of $23.35+/-1.14 \mathrm{~mm}$, in another study conducted at Baylor College of Medicine in Houston, in three compared groups, the axial length was $23.62+/-0.53,23,77+/-0.61$ and $23.94+/-0.52 \mathrm{~mm}$ consecutively and look quite similar to our series results.[23,24] 
Owing to limited experience, the surgeon did not use preoperative keratometry to decide the incision location until late in the year. There is enough evidence that surgical incision made at the steepest meridian reduce postoperative astigmatism.[25-28]

The rate of capsular rupture in our series $(4.31 \%)$ remains slightly higher compared to other series but was within the desirable limit of less than $5 \%$. It was $3.2 \%$ in the trainee group versus $1.6 \%$ in the consultants' group arms of the RCO database cataract surgery study, $2.2 \%$ in Auckland study, $3.8 \%$ in the Cadiz study. The zonular disruption happened in one patient's eye. It was limited to one clock hour (4 to 5 o'clock) and did not affect the IOL stability during the follow-up period.

Corneal oedema noted in seven eyes $(6,03 \%)$ was mostly due to phacoemulsification of a hard nucleus in 6 eyes and a shallow anterior chamber in one eye. Nucleo-sclerosis grading is a logical way to select patients. However, this was a big omission the surgeon. No cataract classification was recorded and could not be analysed to correlate the grade and the likelihood of the corneal oedema. Though there is new evidence supporting phacoemulsification can be performed successfully at any stage of nucleosclerosis, even on hard rock nuclei,[29] the surgical experience matters and it would be advisable to avoid hard nucleus for young surgeons.

The wrong IOL power was the most serious complication. Refraction and audit of the IOL stock concluded the patient received power +21D instead of +18D. For such a "never event" moment, the communication between the surgeon and the patient can be very delicate. Although this event occurred once, it is a subject of great concern in ways IOLs are handled; grouping IOLs together can predispose to such mistakes. The hospital resolved to attach the patient's IOL to their file pre-operatively and perform double confirmation of IOL by the surgeon and their assistant before scrubbing and immediately before insertion during the surgery. IOL exchange was also reported as a complication in the RCO database cataract surgery study.[21]

Although the postoperative day one vision is seldom reported, it was important for the surgeon to monitor how much he could expect in the early recovery time. In spite of a small drop in $6 / 6$ visual acuity eyes six weeks after surgery, we noted the immediate visual outcomes were as good as the final uncorrected visual acuity ( $p$-value: 0.469 ) but lower than the final best -corrected visual acuity (P-value<0.001). In fact, the Blue Mountains Eye Study concluded there was generally a myopic shift in eyes operated for cataract observed for 5 years.[30]

There was no correlation between eye laterality with final vision (P-value: 0.861); the surgeon was comfortable to operate on either eye.

The number of complications that occurred during this study did not affect the final visual acuity (Pvalue: 0.681 ), unlike co-morbidities that were associated with poor vision (Pearson: -0.614, P-value: 0.01). In the RCO database study, glaucoma, macular degeneration, and diabetic retinopathy were responsible for $72 \%$ of eyes that had worse visual acuity after surgery. A similar conclusion was noted elsewhere.[6,15,19,21,31] 
Analysing the final best-corrected visual acuity, the results met the WHO recommendations and are comparable to other big database outcomes from well-equipped countries and private hospitals. In the RCO database study, postoperative visual acuity showed that $44 \%$ and $89 \%$ of all eyes achieved 0.00 and 0.30 Log MAR or better. Earlier in 2011, the outcomes from the European Registry of Quality Outcomes for Cataract and Refractive Surgery (EUREQUO) showed a BCVA of 6/12 or better in $94.4 \%$ of 241136 cataract extractions. Using the cut-off of 0.30 Log MAR for the BCVA, we also achieved a good rate of 96.6\%. Private clinics in Nigeria, Egypt, Saudi Arabia, also reported good visual acuity achievements. $[6,18,19,23,31,32]$

There was a significant rate of postoperative refractive error. The surgeon never targeted a postoperative refractive error of more than-1D even in cases where monovision was desired. In the literature, postoperative spherical equivalence ranging between $-1.5 \mathrm{D}$ and $+1 \mathrm{D}$ is usually accepted as a good outcome.[23] Using this target in our series, $80.2 \%$ of eyes achieved a good postoperative refractive error. Refractive errors of less than $-3 D$ or more than $+2 D$ were reported as a gross miscalculation in the Saudi Arabia study and amounted to $0.5 \%$ and $2.7 \%$ respectively. There was no power exceeding $+1.75 \mathrm{D}$ in our study.

\section{Conclusions}

The surgeon not only met the WHO recommendations for visual outcomes but also achieved comparable results to those of well-equipped countries and other private hospitals in Africa.

The participants had poorer pre-operative vision compared to other phacoemulsification surgery outcomes studies.

The complications encountered did not affect the final visual outcomes unlike the comorbidities.

There was a negative correlation between comorbidities and final visual outcomes as reported elsewhere by many researchers.

Hence, it is possible to train many phacoemulsification cataract surgeons in Africa without compromising surgical outcomes. This model has the merit of being cheap and sustainable. Moreover, the cultural barriers that usually affect overseas training can be solved in the same way.

However, a significant number of eyes had a postoperative refractive error, and biometry may need to be improved.

The surgeon did not use the nucleo-sclerosis grading system that would have allowed him to predict objectively which eyes had a higher risk for corneal oedema because of excessive phaco energy.

We recommend a study on the surgically induced astigmatism in this dataset and a multicentric study that will serve as a national database for phacoemulsification cataract surgery outcomes in Kenya. 


\section{Strengths}

This study audited a one-year performance of a young phacoemulsification cataract surgeon who trained in the same hospital and reported various results making it a comprehensive surgical audit. Since phacoemulsification cataract surgery outcomes in Kenya and Africa have been poorly reported up to date, this study adds to the body of knowledge on phacoemulsification and will be used in the future to benchmark the progress of this technique.

\section{Limitations}

The sample size is small; this was influenced by the desire to report specifically a one-year study surgical performance.

Six weeks follow up is too short, other studies reported late complications like retinal detachment in eyes that had posterior capsule rupture intraoperatively.

This study reported only visual outcomes as criteria of achievement. However, that may be different from patients' satisfaction level or improvement of their quality of life (QOL). We recommend more studies to investigate whether patients who had phacoemulsification technique report better QOL than those who are operated with manual small incision cataract surgery.

This study did not compare the surgeon's performance to any other surgeon who trained in a different country. The performance cannot be solely attributed to the fact the training was organized in a local center; therefore, the conclusion can only be qualitative at best.

\section{Declarations}

Authors' contribution:

J. C. Niyonzima is the principal investigator; wrote the research project and analyzed the data

S. Gichuhi discussed each step of this research from the project phase till its conclusion

S. Sitati is the phacoemulsification surgery technique trainer and participated in the discussion of this article.

E. Ollando participated in the discussion and corrected the final manuscript

Publication consent: yes

Competing interests: none of the authors has competing interests.

Funding: none.

Page 13/19 
Data availability: provided with the article as supplementary file

Acknowledgments: This research project was assessed and approved by the University of Edinburgh, $\mathrm{CHM}$ Ophthalmology. We thank the faculty members for all their contributions. Misses Belindah Cherono and Pauline R. Otunga, played a key role in data collection.

\section{References}

1 Spiteri A, Aggarwal R, Kersey T, et al. Phacoemulsification skills training and assessment. Br J Ophthalmol 2010;94:536-41. doi:10.1136/bjo.2009.159715

2 Razavi H, Turner E, Shah S, et al. Preoperative visual acuity among cataract surgery patients and countries' state of development: a global study. Bull World Health Organ 2011;89:749-56. doi:10.2471/blt.10.080366

3 Dua HS, Said DG, Otri AM. Are we doing too many cataract operations? Cataract surgery: A global perspective. Br J Ophthalmol 2009;93:1-2. doi:10.1136/bjo.2008.143685

4 Cook C, Carrara H, Myer L. Phaco-emulsification versus manual small-incision cataract surgery in South Africa. South African Med J 2012;102:537-40.

5 Masum A, Khan K, Hossain A. Visual Outcomes and Complications of Small Incision Cataract Surgery (MICS) in a Peripheral CMH. JAFMC Bangladesh 2014;10:14-8.

6 Alasbali T, Alsharif A, Al-Gehaban S, et al. Cataract surgery audit at a private hospital in Saudi Arabia. Middle East Afr J Ophthalmol 2015;22:502. doi:10.4103/0974-9233.167820

7 Lotfipour M, Rolius R, Lehman EB, et al. Trends in cataract surgery training curricula. J Cataract Refract Surg 2017;43:49-53. doi:10.1016/j.jcrs.2016.10.020

8 Palmer JJ, Chinanayi F, Gilbert A, et al. Trends and Implications for achieving VISION 2020 human resources for eye health targets in 16 countries of sub-Saharan Africa by the year 2020. Hum Resour Health 2014; 12:45. doi:10.1186/1478-4491-12-44

9 Lindfield R, Ngounou F, Vishwanath K, et al. The challenges in improving outcome of cataract surgery in low and middle income countries. Indian J Ophthalmol 2012;60:464. doi:10.4103/0301-4738.100552

10 J. Z, R. S, L. J, et al. Visual acuity and quality of life outcomes in patients with cataract in Shunyi County, China. Am J Ophthalmol 1998;126:515-23. doi:10.1016/S0002-9394(98)00274-8

11 World Health Organization. Informal consultation on analysis of blindness prevention outcomes. Geneva WHO. 1998;:1-23. doi:ISBN9789242547123 
12 Lee A. Assessing Surgical Skills. Ophthalmology 2006;113:505-6. doi:10.1111/j.1365277x.2007.00801.x

13 Manning S, Barry P. Benefits of the European Registry of Quality Outcomes for Cataract and Refractive Surgery to an ophthalmology trainee: How an ophthalmology trainee used EUREQUO to audit their surgical training. J Cataract Refract Surg 2014;40:157-9. doi:10.1016/j.jcrs.2013.11.006

14 Megaw R, Rane-Malcolm T, Brannan S, et al. Revalidation and electronic cataract surgery audit: A Scottish survey on current practice and opinion. Eye 2011;25:1471-7. doi:10.1038/eye.2011.203

15 Royo-Dujardin L, Alcalde-Vílchez E, Rodríguez-de la Rúa E, et al. Audit of cataract surgery in Cadiz: visual outcomes and complications. Arch Soc Esp Oftalmol 2018;93.274-82.

doi:10.1016/j.oftal.2017.12.005

16 Sumathi M, Jiwon P, Ghanshyam P, et al. Cataract Surgery Visual Outcomes and Associated Risk Factors in Secondary Level Eye Care Centers of L V Prasad Eye Institute, India Sumathi. PLoS Med 2016;:1-11. doi:10.1371/journal.pone.0144853 January

17 Sherwin JC, Dean WH, Schaefers I, et al. Outcomes of manual small-incision cataract surgery using standard 22 dioptre intraocular lenses at Nkhoma Eye Hospital, Malawi. Int Ophthalmol 2012;32:341-7. doi:10.1007/s10792-012-9565-x

18 Oderinlo 0 , Hassan A, Oluyadi F, et al. Refractive aim and visual outcome after phacoemulsification: A 2-year review from a Tertiary Private Eye Hospital in Sub-Saharan Africa. Niger J Clin Pract 2017;20:14752. doi:10.4103/1119-3077.183249

19 Kim BZ, Patel D V., McGhee CNJ. Auckland cataract study 2: clinical outcomes of phacoemulsification cataract surgery in a public teaching hospital. Clin Exp Ophthalmol 2017;45:584-91.

doi:10.1111/ceo.12922

20 Theodoropoulou S, Grzeda MT, Donachie PHJ, et al. The Royal College of Ophthalmologists' National Ophthalmology Database Study of cataract surgery. Report 5: Clinical outcome and risk factors for posterior capsule rupture and visual acuity loss following cataract surgery in patients aged 90 years and old. Eye Published Online First: 2019. doi:10.1038/s41433-019-0389-z

21 Day AC, Donachie PHJ, Sparrow JM, et al. The Royal College of Ophthalmologists' National Ophthalmology Database study of cataract surgery: Report 1, visual outcomes and complications. Eye 2015;29:552-60. doi:10.1038/eye.2015.3

22 Gabbott T, Roberts H, Briesen S. Assessing the fear of cataract surgery in rural Kenya. Cogent Med 2019;6:6-13. doi:10.1080/2331205x.2019.1607434

23 Briesen S, Roberts $\mathrm{H}$, Lewallen S. The importance of biometry to cataract outcomes in a surgical unit in Africa. Ophthalmic Epidemio/2010;17:196-202. doi:10.3109/09286586.2010.498662 
24 Gökce SE, Montes De Oca I, Cooke DL, et al. Accuracy of 8 intraocular lens calculation formulas in relation to anterior chamber depth in patients with normal axial lengths. $J$ Cataract Refract Surg 2018;44:362-8. doi:10.1016/j.jcrs.2018.01.015

25 Jauhari N, Chopra D, Chaurasia RK, et al. Comparison of surgically induced astigmatism in various incisions in manual small incision cataract surgery. Int J Ophthalmol 2014;7:1001-4. doi:10.3980/j.issn.2222-3959.2014.06.16

26 Borasio E, Mehta JS, Maurino V. Surgically induced astigmatism after phacoemulsification in eyes with mild to moderate corneal astigmatism: temporal versus on-axis clear corneal incisions. $J$ Cataract Refract Surg 2006;32:565-72. doi:10.1016/j.jcrs.2005.12.104

27 Özyol E, Oz̈yol P. Analyses of surgically induced astigmatism and axis deviation in microcoaxial phacoemulsification. Int Ophthalmol 2014;34:591-6. doi:10.1007/s10792-013-9858-8

28 Rho CR, Joo C. Effects of steep meridian incision on corneal astigmatism in phacoemulsification cataract surgery. Published Online First: 2011. doi:10.1016/j.jcrs.2011.11.031

29 Foster GJL, Allen QB, Ayres BD, et al. Phacoemulsification of the rock-hard dense nuclear cataract: Options and recommendations. J Cataract Refract Surg 2018;44:905-16. doi:10.1016/j.jcrs.2018.03.038

30 Guzowski M, Rochtchina E, Wang JJ, et al. Refractive changes following cataract surgery: the Blue Mountains Eye Study. Clin Exp Ophthalmol 2002;30:159-62.

31 Sonron E, Tripathi V, Bridgemohan P, et al. A retrospective study on the outcomes of cataract surgery in an Eastern Regional Health Authority hospital of Trinidad and Tobago. PeerJ 2015;3:e1222. doi:10.7717/peerj.1222

32 El-Lakkany T, Swellam A, Abd El-Hameed $\mathrm{H}$, et al. Outcomes of bimanual microincision cataract surgery and 2.2-mm coaxial phacoemulsification. J Egypt Ophthalmol Soc 2018;111:82. doi:10.4103/ejos.ejos_47_17

\section{Figures}




\section{comparison of postoperative uncorrected vision: study vs}

WHO recommendations

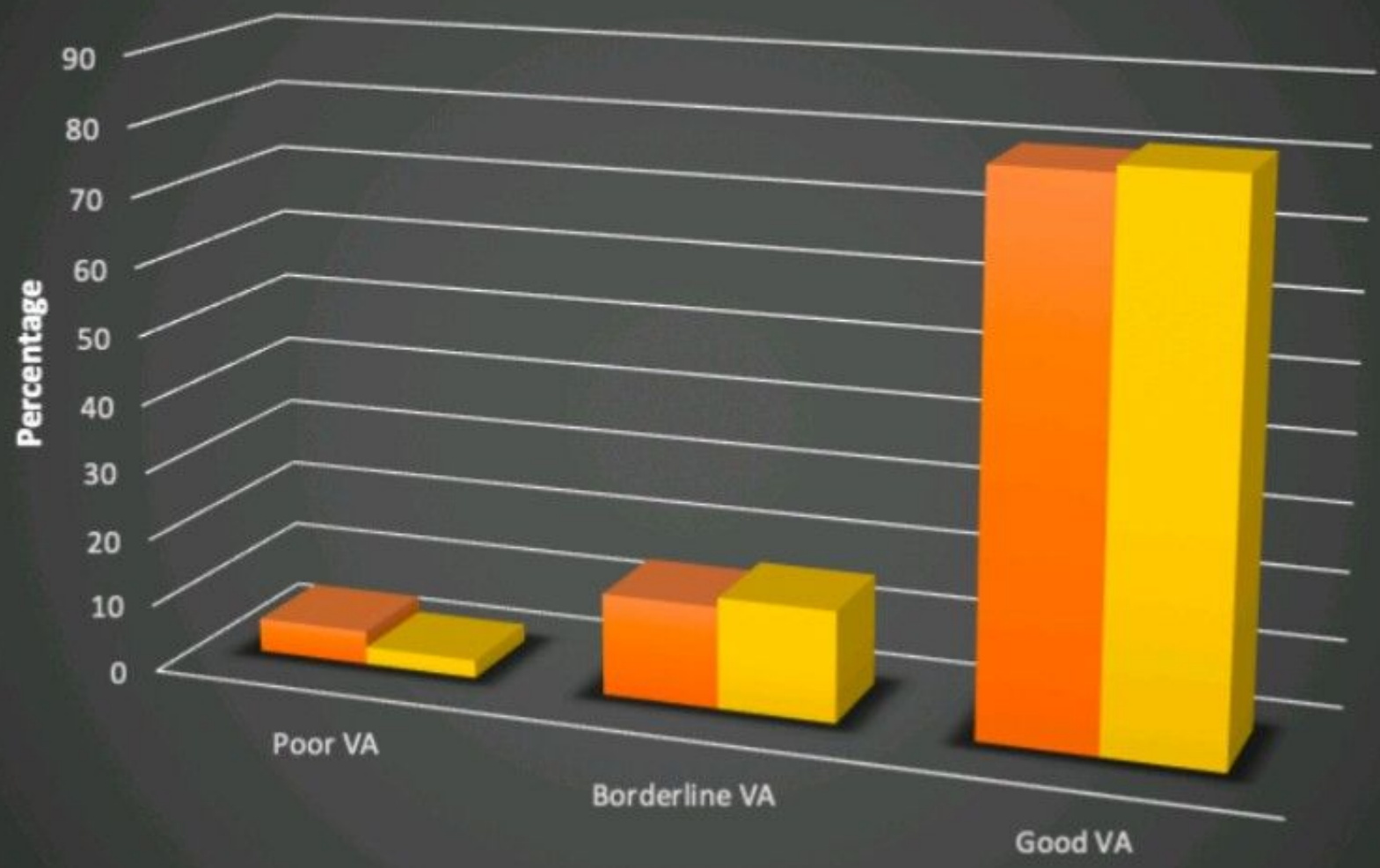

Figure 1

uncorrected visual acuity, study vs WHO 


\section{Comparison of postoperative best corrected vision :study vs}

WHO recommendations

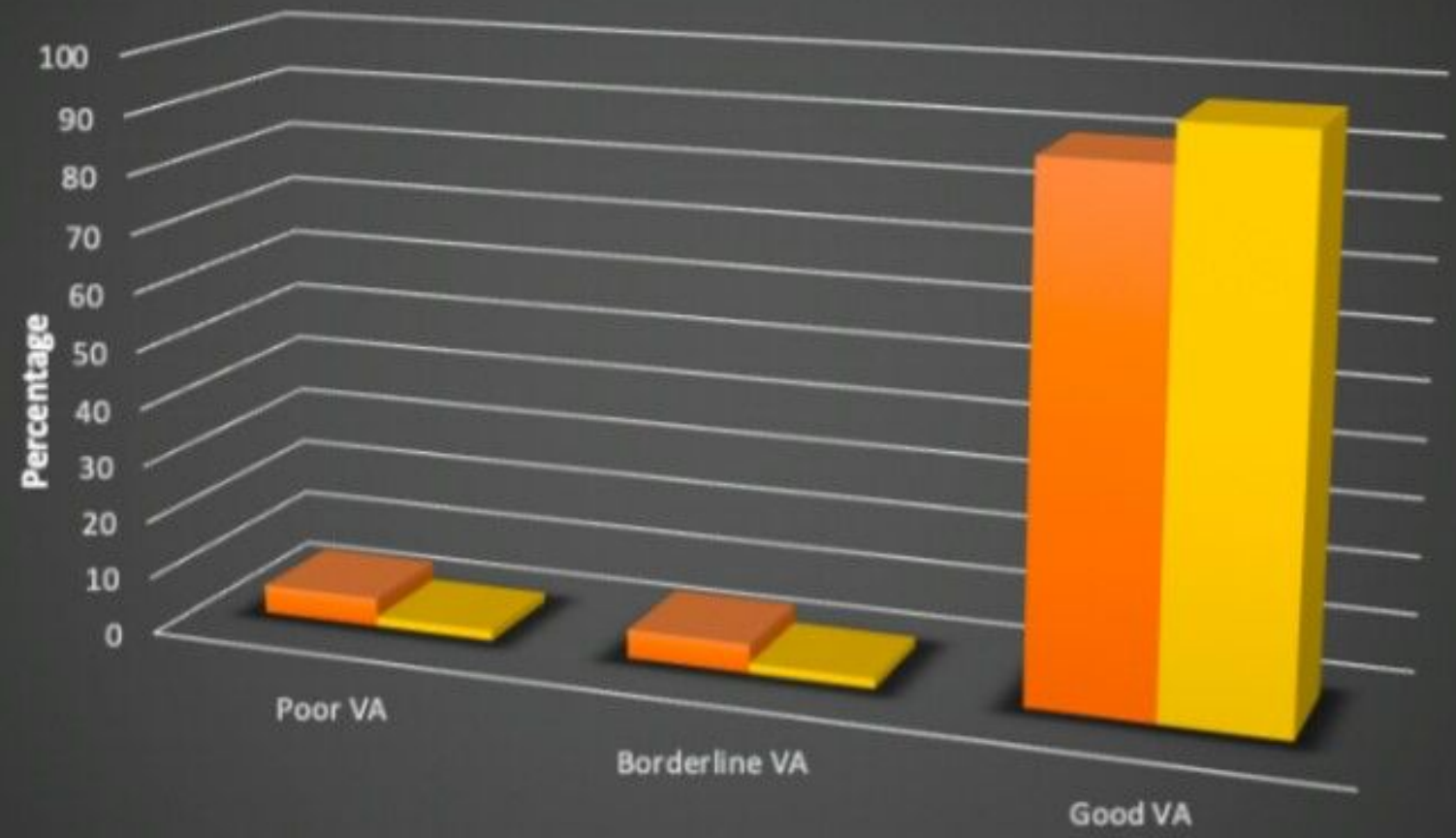

Figure 2

best corrected visual acuity, Study vs WHO

Postoperative refractive error (spherical equivalence)

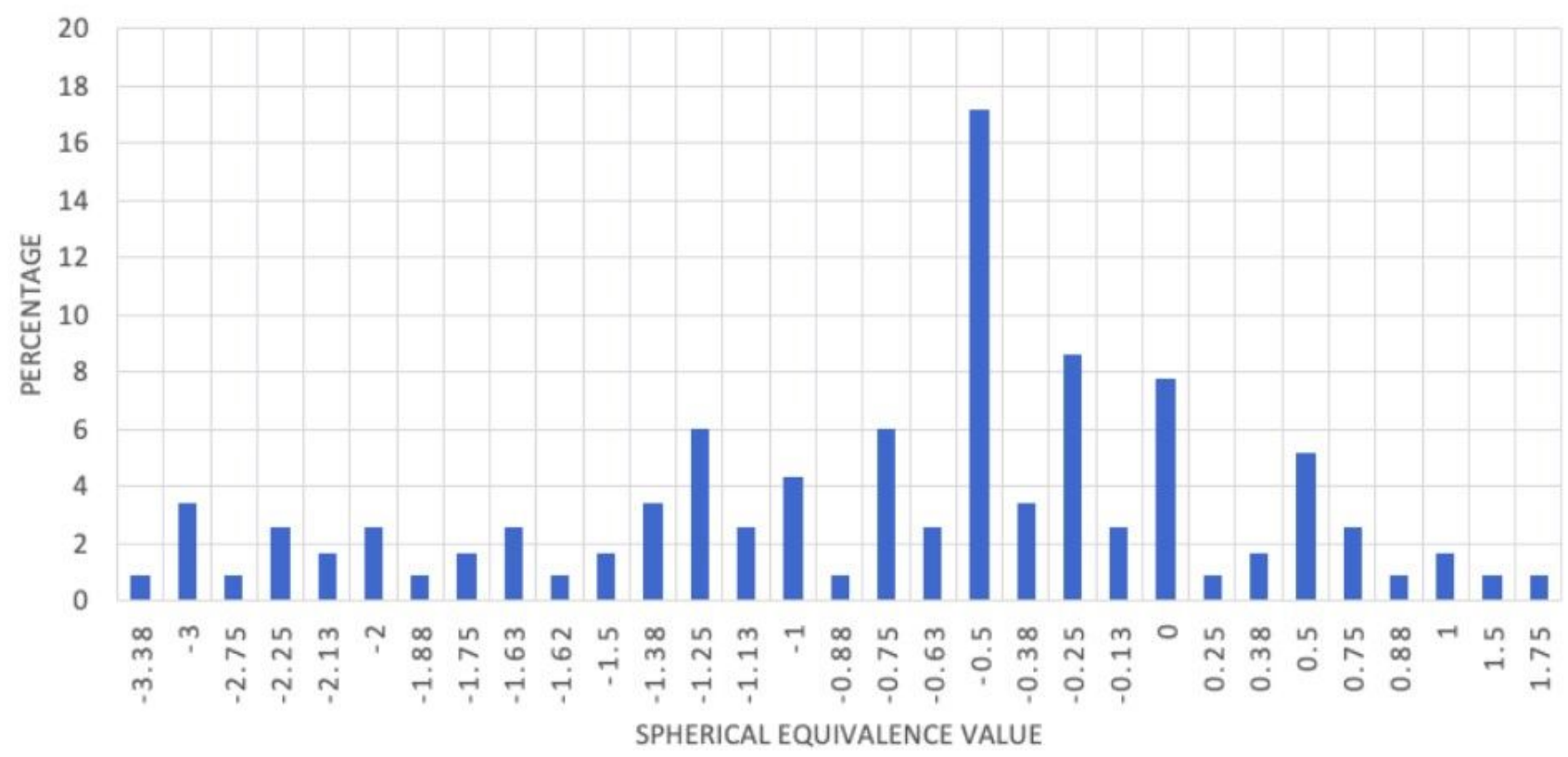


Figure 3

Postoperatative refractive error

\section{Supplementary Files}

This is a list of supplementary files associated with this preprint. Click to download.

- DATACOLLECTIONPAULINEwithcorrections.xIsx 